\title{
Cytokine Synergism in Apoptosis: Its Role in Diabetes and Cancer
}

\author{
Myung-Shik Lee* \\ Department of Medicine, Samsung Medical Center, Sungkyunkwan University School of Medicine and \\ National Research Laboratory of Cell Death and Diabetes Research, Seoul 135-710, Korea
}

Received 15 September 2001

\begin{abstract}
The effects of individual cytokine on apoptosis have been extensively studied. However, the effect of the cytokine combination, or the synergistic effect of cytokines on cell death, has not been widely studied, though synergism between cytokines has been documented in a variety of biological situations. In our effort to identify the final death effector molecule(s) in autoimmune diabetes, we inadvertently became interested in the cytokine synergism. We discovered that IFN $\gamma / \mathrm{TNF} \alpha$ synergism, rather than the Fas ligand as currently believed, is responsible for the apoptosis of pancreatic islet cells both in vitro and in vivo. We also studied similar cytokine synergism in cancer cell deaths, and noted the similarities and dissimilarities between cancer cell death and islet cell death.
\end{abstract}

Keywords: Apoptosis, Diabetes, Cancer, Cytokine, Synergism

The role of the Fas ligand in pancreatic $\beta$-cell death and diabetes

Previous adoptive transfer experiments have clearly shown that autoreactive $\mathrm{T}$ lymphocytes are the most important, as well as the final effector cells in autoimmune diabetes (Wicker et al., 1986; Haskins and McDuffie, 1990; Wang et al., 1991). Effector $\mathrm{T}$ cells induce apoptosis of insulin producing pancreatic $\beta$-cells. This then leads to absolute insulindeficiency and clinically manifest diabetes, at least in the murine model of the autoimmune diabetes-NOD (nonobese diabetic) mice. However, it was not clearly demonstrated which effector molecule(s) on the effector $\mathrm{T}$ lymphocytes exert cytotoxicity on pancreatic $\beta$-cells. Recent works have demonstrated that effector $\mathrm{T}$ lymphocytes exert cytotoxicity upon target cells using mainly two independent arms. One is the perforin-granzyme B pathway, and the other is the Fasmediated pathway. Both of them eventually lead to apoptosis of the target cells (Henkart, 1994; Ju et al., 1994; Kagi et al.,

*To whom correspondence should be addressed.

Tel: 82-2-3410-3436; Fax:82-2-3410-0388

E-mail: mslee@smc.samsung.co.kr
1994). The perforin pathway has been implicated in both the natural and artificial autoimmune diabetes models (Kagi et al., 1996; Kagi et al., 1997). Evidence suggesting the involvement of Fas-mediated apoptosis in the development of autoimmune diabetes was also reported (Yamada et al., 1996; Chervonsky et al., 1997; Itoh et al., 1997). However, the involvement of Fas-mediated apoptosis in the development of autoimmune diabetes is controversial. Previous reports that lymphocytes from diabetic NOD mice were unable to induce diabetes in Fas-deficient NOD-lpr/lpr mice were regarded as evidence that Fas-mediated apoptosis is necessary for $\beta$-cell apoptosis and diabetes in NOD mice (Chervonsky et al., 1997; Itoh et al., 1997). However, NOD-lpr/lpr mice are not the optimal recipients for diabetes transfer because of the artifactual effect of the Fas knockout. Massive accumulation of abnormal B220+, CD4-, CD8- cells that constitutively express the Fas ligand (FasL) (Chu et al., 1995; Watanabe et al., 1995), and their persistence after sublethal irradiation (Reap et al., 1997), will constitute an adverse environment for the transferred lymphocytes and affect the outcome of lymphocyte transfer. Thus, experiments that obviate such artifactual effects should be carried out to show the role of Fas in autoimmune diabetes. Thus, we employed the strategy of administering a blocking type anti-FasL antibody to NOD mice that does not involve artifactual effects of the Fas knockout. Then, the K10 antiFasL antibody administration did not affect the diabetes incidence in NOD mice after an adoptive transfer of diabetogenic lymphocytes or cyclophosphamide administration. This strongly indicates that FasL is not the dominant effector molecule in pancreatic $\beta$-cell apoptosis by autoreactive T cells (Kim et al., 1999).

In order to confirm that the absence of Fas on $\beta$-islet cells does not affect their autoimmune destruction, not only in accelerated diabetes but also in natural diabetes of NOD mice, the pancreata from neonatal NOD-lpr/lpr mice were transplanted under the kidney capsule of the diabetic NOD mice. Grafted pancreata were almost completely destroyed 4 weeks after the transplantation with massive lymphocyte infiltration into the graft and abortive islet formation. This indicates that Fas on islet cells is not necessary for the 
autoimmune destruction of $\beta$-cells (Kim et al., 1999). This neonatal islet graft model has the advantage of obviating abnormal artifactual effects of the Fas knockout, such as a massive accumulation of double-negative $\mathrm{T}$ cells that was observed when the NOD-lpr/lpr mouse model is employed.

Thus, our results are contrary to other papers that report the crucial role of Fas-FasL interaction in pancreatic $\beta$-cell apoptosis of autoimmune diabetes. To resolve this paradox on the role of Fas-mediated apoptosis in autoimmune diabetes, we conducted an investigation that was based on the hypothesis that the resistance to diabetes transfer in NOD-lpr/ lpr mice that was observed by others is due to abnormal (double-negative) lymphocytes in the NOD-lpr/lpr mice (Wofsy et al., 1984). First, we addressed why diabetes cannot be transferred to the NOD-lpr/lpr mice, despite our observation of the non-essential role of Fas in b-cell apoptosis. We noticed that lymphocytes from the NOD-lpr mice were constitutively expressing a huge amount of FasL on the abnormal double-negative lymphocytes in the NOD-lpr/lpr mice. A decrease in the number of FasL+ lymphocytes by neonatal thymectomy facilitated the development of insulitis. Furthermore, co-transfer of FasL-expressing lymphocytes from the NOD-lpr/lpr mice completely abrogated diabetes after an adoptive transfer of lymphocytes from the diabetic NOD mice. The inhibition of diabetes by co-transferred lymphocytes was reversed by an anti-FasL antibody. This conclusively suggests that FasL on abnormal lymphocytes from the NOD-lpr/lpr mice was responsible for the inhibition of the diabetes transfer, and that FasL is not an effector molecule in islet cell death (Fig. 1) (Kim et al., 2000).

From these results, we could show that FasL is not the

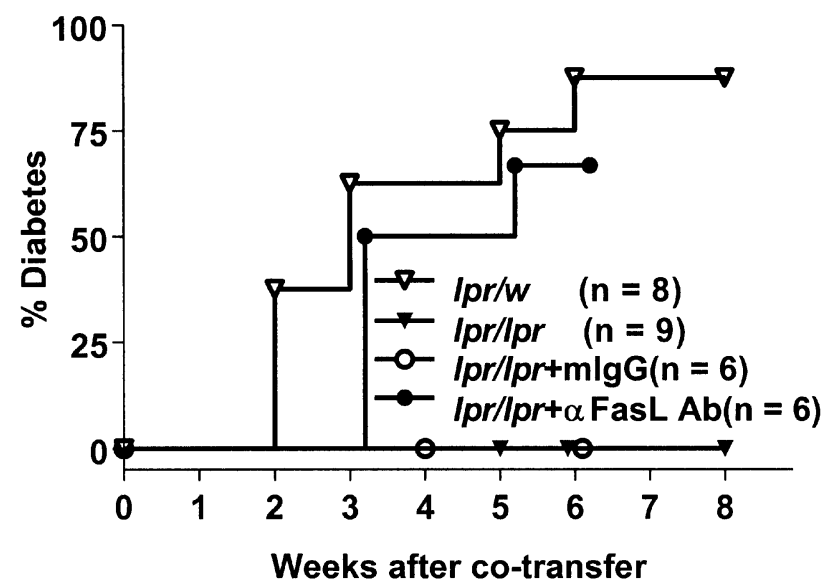

Fig. 1. Inhibition of diabetes transfer by FasL+ lymphocytes from NOD-lpr/lpr mice. They completely abrogated diabetes after the adoptive transfer of lymphocytes from diabetic NOD mice. The inhibition was reversed by anti-FasL antibody treatment. This indicates that FasL on lymphocytes from NOD$l p r / p r$ mice was responsible for the inhibition of diabetes transfer. The control antibody did not affect the abrogation of diabetes transfer by FasL+ lymphocytes. (From J. Immunol. 164, 2931, 2000 with permission) major apoptotic effector molecule in pancreatic $\beta$-cell apoptosis. We could also address why other investigators reached the conclusion that FasL is the main apoptotic effector in autoimmune diabetes. However, our data was more than a simple resolution of the previous paradox. Because the FasL-expressing abnormal double-negative lymphocytes could inhibit diabetes development after an adoptive transfer of splenocytes, FasL could be visualized as a potential therapeutic agent against autoimmune diabetes by perhaps inducing apoptosis on autoreactive $\mathrm{T}$ cells. However, the FasL-expressing cells themselves could not be used as therapeutic agents, because such cells induced hepatitis in the recipient mice. These results were expected from previous reports that showed fulminant hepatitis after an injection of an agonistic anti-Fas antibody, and unusual vulnerability of hepatocytes to the Fas-mediated apoptosis. Thus, we employed the strategy of ex vivo treatment of diabetogenic lymphocytes with soluble FasL that has the advantage of obviating in vivo administration of FasL. Consistent with our hypothesis and expectation, pretreatment of lymphocytes with human soluble FasL (sFasL) significantly inhibited diabetes transfer without causing hepatitis (Kim et al., 2000). These results suggest the potential therapeutic role of soluble FasL in autoimmune disorders that include but are not limited to autoimmune diabetes. Our data also suggest that (human) sFasL has some effect on unmanipulated peripheral lymphocytes, contrary to previous reports that Fas on unmanipulated peripheral lymphocytes is nonfunctional. We further investigated the immunological mechanism of the sFasL-mediated prevention of autoimmune diabetes. sFasL is cleaved from membrane-bound FasL by matrix metalloprotease. Human sFasL has an apoptotic activity, while the murine one has no apoptotic activity. The physiological role of human sFasL has not been clarified, while the pathological consequence of sFasL overproduction was reported (hepatitis in some forms of leukemia) (Tanaka et al., 1996). However, it makes no sense that the human lymphoid system would elaborate functional sFasL in order to cause systemic tissue injury since this does not occur in the mouse lymphoid system. In our effort to resolve this issue, we found that the sFasL treatment significantly decreased the CD45RB ${ }^{10}$ 'memory' CD4+ lymphocyte fraction, and increased

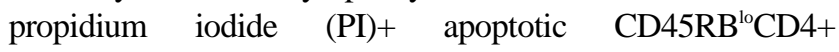
lymphocytes among murine peripheral lymphocytes. This suggests that sFasL induces apoptosis on the CD4+CD45RB ${ }^{\text {lo }}$ memory cells. However, the sFasL treatment neither decreased the CD45RO+ 'memory' CD4+ lymphocyte fraction, nor did it increase the PI+ CD45RO+CD4+ lymphocytes, among human peripheral lymphocytes. This suggests that the deletion of memory cells by sFasL had already occurred in vivo (Kim et al., 2001). These results suggest that the physiological function of human sFasL is to delete the potentially autoreactive 'memory' lymphocytes, which complements the membrane FasL (mFasL)-mediated deletion of autoreactive cell in human beings, but not in mice. 
(A)
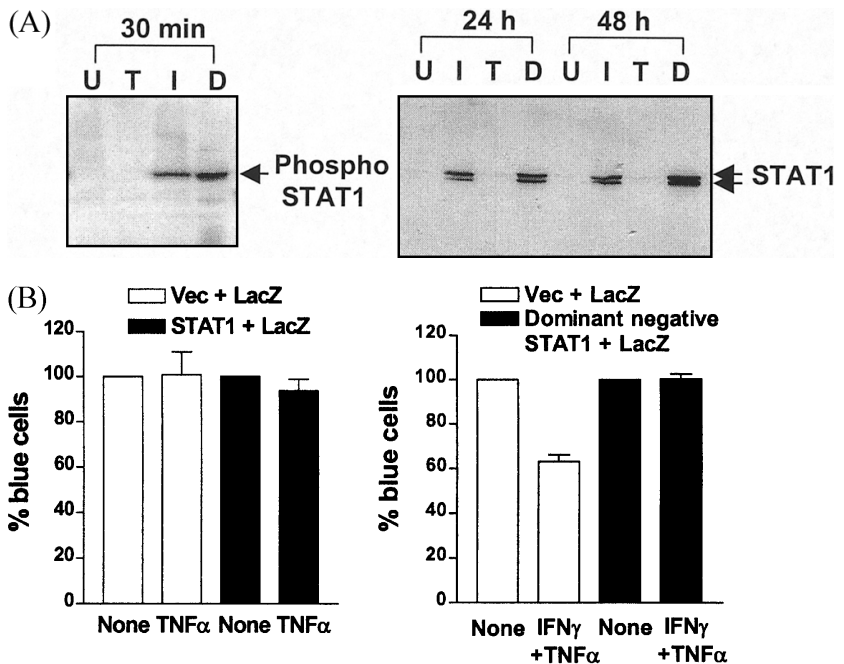

Fig. 2. Induction of STAT1 by IFN $\gamma$ and the role of phosphorylated STAT1 in IFN $\gamma /$ TNF $\alpha$ synergism. (A) After the MIN6N8 cells were left untreated (U) or treated with IFN $\gamma$ (I, $1,000 \mathrm{U} / \mathrm{ml}), \mathrm{TNF} \alpha(\mathrm{T}, 10 \mathrm{ng} / \mathrm{ml})$, or IFN $\gamma$ plus TNF $\alpha$ (D) for the indicated time, the cell lysates were prepared for the detection of phosphorylated STAT1, unphosphorylated STAT1 by a western blot analysis. Two isoforms of unphosphorylated STAT1 (STAT1 $\alpha$ and STAT1 $\beta$ ) were detected (arrows). Phosphorylated STAT1 and unphosphorylated STAT1 were detected $30 \mathrm{~min}$ and $24-48 \mathrm{~h}$, respectively, after treatment with IFN $\gamma$ or IFN $\gamma / \mathrm{TNF} \alpha$, but not with TNF $\alpha$ alone. (B) To evaluate the role for STAT1 in the cytokine synergism, MIN6N8 cells were transiently co-transfected with STAT1 plus the LacZ gene (left), or dominant negative STAT1 plus LacZ (right). At $48 \mathrm{~h}$ after transfection, the cells were treated for $72 \mathrm{~h}$ with either $\mathrm{TNF} \alpha(10 \mathrm{ng} / \mathrm{ml})$ alone or IFN $\gamma(1,000 \mathrm{U} / \mathrm{ml})$ plus TNF $\alpha(10$ $\mathrm{ng} / \mathrm{ml})$. Transfection with STAT1 did not induce susceptibility to TNF $\alpha$ in insulinoma cells (left), while transfection with dominant-negative STAT1 abolished sensitivity to the IFN $\gamma / \mathrm{TNF} \alpha$ combination (right). "Vec" indicates an empty vector control. The number of blue cells in untreated wells was set to $100 \%$. (From J. Immunol. 166, 4481, 2001 with permission)

\section{IFN $\gamma /$ TFN $\alpha$ synergism in pancreatic $\beta$-cell death}

Next, we studied which cytokine (combination) could lead to pancreatic $\beta$-cell death if FasL is not the main death effector in pancreatic $\beta$-cell apoptosis. FasL was found to have no effect on the islet cell viability in vitro. This is consistent with our in vivo findings described previously (Lee et al., 1999). A combination of IFN $\gamma$ and $\mathrm{TNF} \alpha$, but not either of the cytokines alone, induced a classical apoptosis in murine insulinoma and pancreatic islet cells. This is indicated by the Hoechst staining, DNA ploidy assay, as well as the EM and DNA fragmentation pattern. Furthermore, pan-caspase inhibitors abrogated insulinoma cell death by the IFN $\gamma / \mathrm{TNF} \alpha$ combination and caspase substrate cleavage was observed using DEVD-AMC. This suggests that the IFN $\gamma / \mathrm{TNF} \alpha-$ induced insulinoma cell death is a classical caspase-dependent apoptosis. IL-1 $\beta$ had a negligible effect on islet cell death. The
IFN $\gamma$ treatment conferred susceptibility to TNF $\alpha$-induced apoptosis on otherwise resistant insulinoma cells by STAT1 activation, followed by the induction of STAT1 and IRF-1 (Fig. 2A). Transfection of phosphorylation-defective STAT1 abrogated islet cell apoptosis by the IFN $\gamma / \mathrm{TNF} \alpha$ combination, which suggests that the STAT1 phosphorylation plays a critical role in mediating IFN $\gamma$-induced induction of TNF $\alpha$ susceptibility (Fig. 2B) (Suk et al., 2001a). However, the transfection of STAT1 failed to induce TNF $\alpha$ susceptibility, which indicates that STAT1 itself, without the STAT1 activation, is insufficient for TNF $\alpha$ susceptibility, contrary to a previous report (Kumar et al., 1997). Possible downstream events that follow the STAT1/IRF-1 activation were studied (Kano et al., 1999). An RT-PCR analysis demonstrated that the expression of caspases- 1 and -11 was induced by IFN $\gamma$, while the constitutive expression of other caspases (caspases$2,-3,-7,-8,-9)$ was unaffected by the cytokine treatment (Suk et al., 2001a). TNF $\alpha$ alone appeared to induce the expression of caspase-11, but not caspase-1. A western blot analysis also showed that caspase- 1 was induced at the protein level by IFN $\gamma$, but not by TNF $\alpha$. Although caspase- 1 has been regarded as a proinflammatory caspase, its involvement in apoptosis has also been described in a number of instances including TNF $\alpha$-mediated apoptosis (Tamura et al., 1995; Enari et al., 1996). Caspase-11 is essential for the activation of caspase-1 by physically interacting with procaspase-1 (Wang et al., 1998). The induction of caspase-11 by IFN $\gamma$ alone or IFN $\gamma / \mathrm{TNF} \alpha$, as observed in this study, might be essential for the apoptosis that is mediated by caspase-1, which itself was induced by IFN $\gamma$. Recent papers reported that caspase-11 activated caspase-3, as well as caspase-1 (Kang et al., 2000). Furthermore, caspase-11-deficient mice were partly resistant to the induction of experimental allergic encephalomyelitis (Hisahara et al., 1997), and to the development of stroke after middle cerebral artery occlusion (Kang et al., 2000). Thus, the IFN $\gamma$-induced caspase-11, as noted in our experiment, may play an important role in the activation of caspase- 3 during the apoptosis of $\beta$-cells.

STAT1 and IRF-1 were expressed in pancreatic islets of the diabetic NOD mice, and co-localized with apoptotic cells. Moreover, an anti-TNF $\alpha$ antibody inhibited the development of diabetes after an adoptive transfer (Fig. 3) (Suk et al., 2001a). Based on the results presented here, we propose that CD4+ $\mathrm{T}$ lymphocytes (a major source of IFN $\gamma$ ) act in collaboration with macrophages (a major source of TNF $\alpha$ ) to induce $\beta$-cell death through a delayed-type hypersensitivity (DTH)-like reaction (Fig. 4). This type of cooperative immune response between the innate and adaptive immune responses may also be responsible for organ-specific autoimmune diseases other than autoimmune diabetes. Altogether, these results indicate that IFN $\gamma / \mathrm{TNF} \alpha$ synergism is responsible for autoimmune diabetes in vivo, as well as $\beta$-cell apoptosis in vitro, and suggest a novel signal transduction in IFN $\gamma / \mathrm{TNF} \alpha$ synergism. 


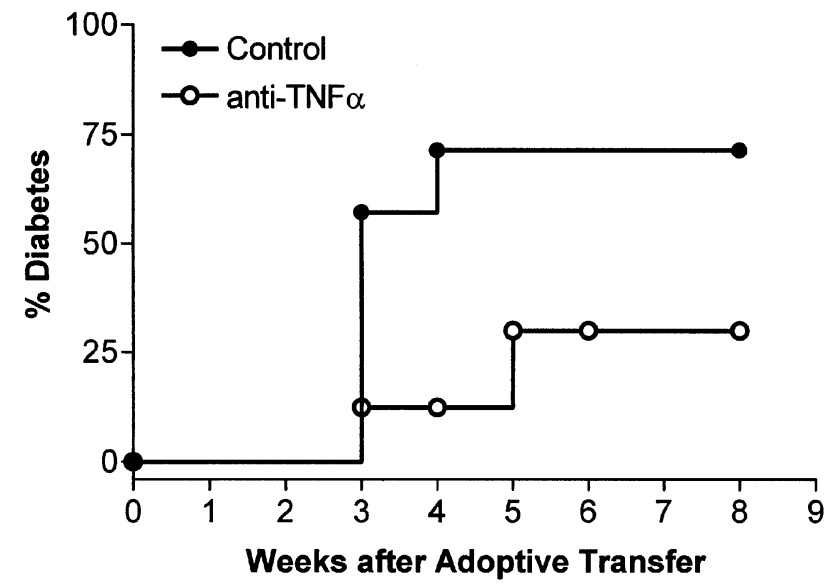

Fig. 3. Blockade of autoimmune diabetes by an anti-TNF $\alpha$ antibody in NOD mice. An anti-TNF $\alpha$ antibody $(0.5 \mathrm{mg})$, or the same volume of control $\mathrm{IgG}$, was administered intraperitoneally during and after the adoptive transfer three times a week. Compared to the control IgG (open circles, $n=9$ ), anti-TNF $\alpha$ antibody administration (solid circles, $\mathrm{n}=10$ ) significantly decreased the incidence of diabetes after the adoptive transfer ( $p$ $<0.05$ ). (From J. Immunol. 166, 4481, 2001 with permission)

\section{IFN $\gamma /$ TFN $\alpha$ synergism in cancer cell death}

Next, we studied IFN $\gamma$ to see if it could confer a similar susceptibility to TNFo-mediated apoptosis on otherwise resistant cancer cells, because IFN $\gamma / \mathrm{TNF} \alpha$ synergism has been reported in numerous tumor cell death models, even before apoptosis itself became a popular topic (Fransen et al., 1986). IFN $\gamma / \mathrm{TNF} \alpha$ synergistically induced the apoptosis of ME-180 human cervical cancer cells, accompanied by DNA fragmentation, characteristic morphological changes in EM, and sub-G1 DNA ploidy. The IFN $\gamma$ pretreatment rendered ME-180 cells sensitive to TNF $\alpha$-induced apoptosis. The IFN $\gamma$ induced phosphorylation of STAT1 and up-regulation of IRF1. Transfection of phosphorylation-defective STAT1 inhibited IFN $\gamma / T N F \alpha$-induced apoptosis, while IRF-1 transfection was sufficient for the induction of TNF $\alpha$ susceptibility. Thus, we postulated that the signal transduction pathway in IFN $\gamma / \mathrm{TNF} \alpha$ synergism seems to be relevant to the cytokine-induced ME180 cancer cell apoptosis model as well as to autoimmune diabetes. However, the roles played by caspases in the ME180 cancer cell death were different than those in autoimmune diabetes. Caspase substrate assays demonstrated that caspase3 and -8 were activated by the IFN $\gamma / \mathrm{TNF} \alpha$ combination. However, the inhibition of caspases by z-VAD-fmk or BDfmk did not inhibit the IFN $\gamma / T N F \alpha$-induced apoptosis. Instead, caspase inhibitors directed the ME-180 cells to undergo necrosis by IFN $\gamma / \mathrm{TNF} \alpha$, which was demonstrated by the Hoechst 33258/propidium-iodide staining and electron microscopy (Fig. 5). These results suggest that IFN $\gamma / T N F \alpha$ synergism appears to execute cell death by unidentified mechanisms other than caspase activation. Caspase activation

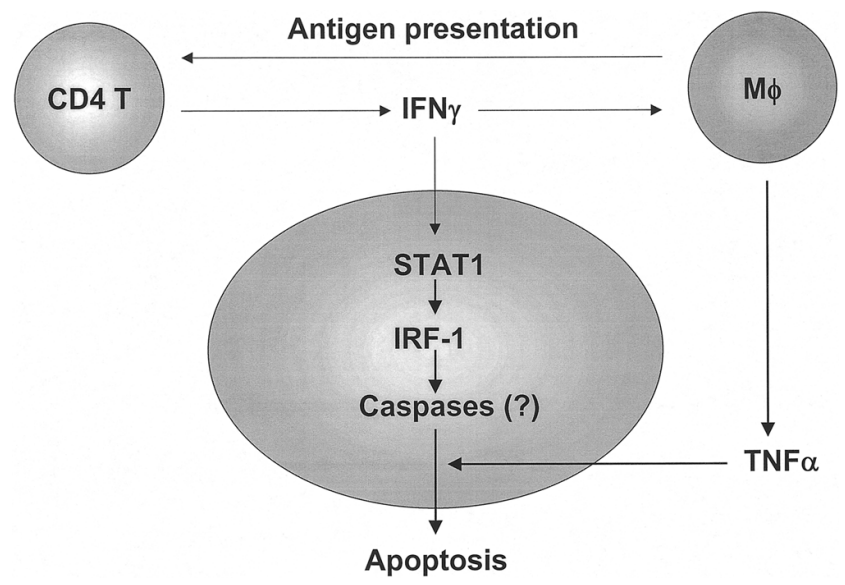

Fig. 4. The DTH-like model in target cell death by inflammatory/immune cytokines. IFN $\gamma$ sensitizes otherwise resistant target cells to TNF $\alpha$-mediated apoptosis by activating/ inducing STAT1/IRF-1/caspases. IFN $\gamma$ is secreted mostly from CD4+ T lymphocytes that represent adaptive immunity. TNF $\alpha$ is primarily from macrophages that represent innate immunity. Thus, concerted action between innate immunity and adaptive immunity might be responsible for pancreatic $\beta$-cell death in autoimmune diseases.
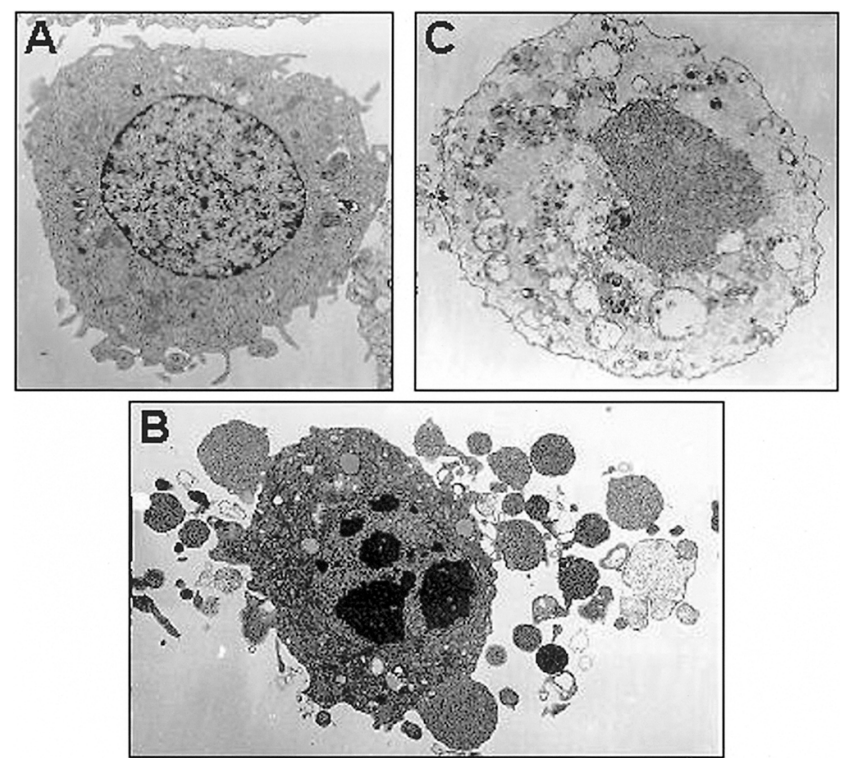

Fig. 5. (A) Control ME- 180 cells without treatment. (B) The IFN $\gamma / T N F \alpha$ combination induced a classical apoptosis on ME180 cervical cancer cells on electron microscopy (IFN $\gamma, 100 \mathrm{U} /$ $\mathrm{ml}$; TNF $\alpha, 10 \mathrm{ng} / \mathrm{ml}$ ). (C) Pretreatment with z-VAD-fmk, a pancaspase inhibitor, did not block the cytokine-induced cytotoxicity, but switched the mode of cell death from apoptosis to necrosis. (From J. Biol. Chem. 276, 13153, 2001 with permission)

may merely dictate morphology of cell death. Besides IFN $\gamma$, IFN $\alpha$ that could activate STAT1 also sensitized ME-180 cells to TNFo-mediated apoptosis (Suk et al., 2001b).

We then studied the role of NF- $\mathrm{KB}$ activation, which could be proapoptotic or antiapoptotic in different situations, in ME- 
(A)
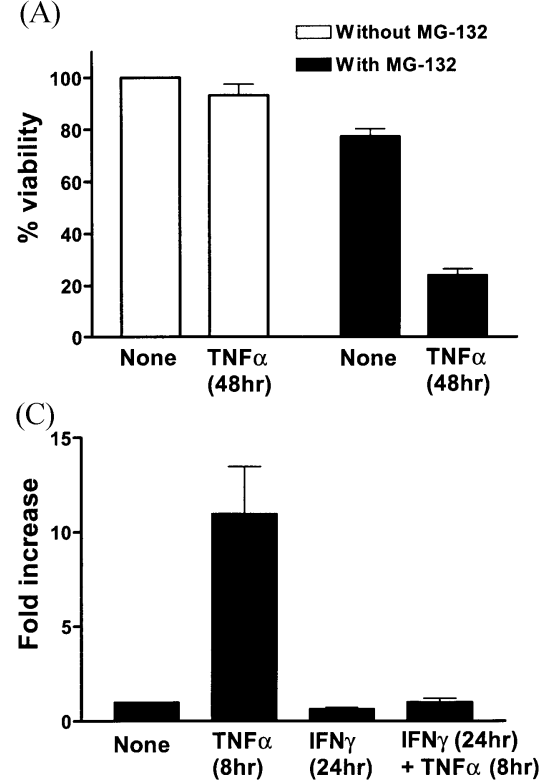
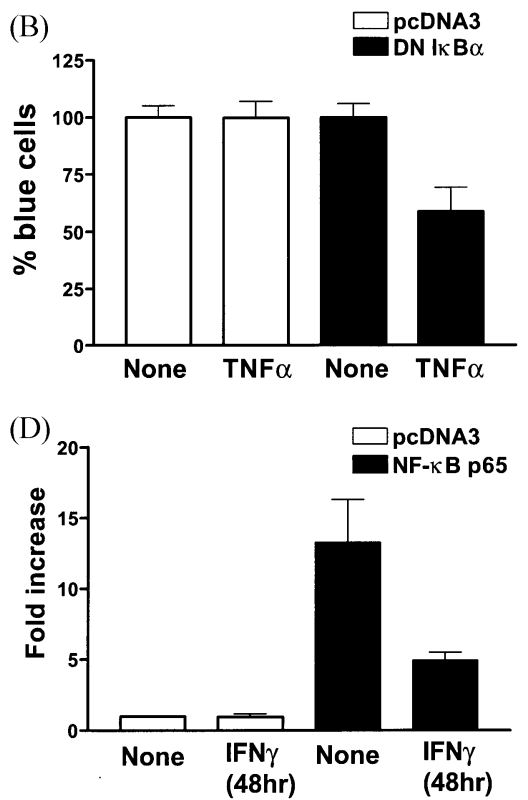

Fig. 6. Inhibition of cytoprotective NF- $\kappa B$ by IFN $\gamma$. (A) Inhibition of NF- $\kappa B$ by a proteasome inhibitor MG 132 sensitized ME-180 cells to TNF $\alpha$. ME-180 cells were treated with either MG $132(0.5 \mathrm{mM})$ alone, or in combination with TNF $\alpha(10 \mathrm{ng} / \mathrm{ml})$ for $48 \mathrm{~h}$. The

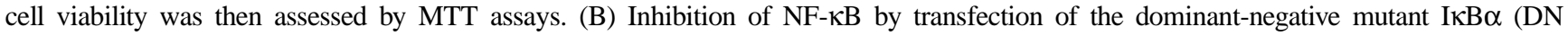
$\mathrm{I} \kappa \mathrm{B} \alpha$ ) also rendered ME-180 cells sensitive to the TNF $\alpha$ treatment. Viability of the ME-180 cells that were co-transfected with the dominant-negative IKB $\alpha$ and lac Z was significantly decreased by the TNF $\alpha$ treatment $(24 \mathrm{~h})$ in contrast to the cells that were cotransfected with an empty vector (pcDNA3) and lacZ. (C, D) NF- $\mathrm{kB}$ reporter assays revealed that pretreatment $(24 \mathrm{~h}, 100 \mathrm{U} / \mathrm{ml}) \mathrm{of}$ the ME-180 cells with IFN $\gamma$ inhibited the TNF $\alpha$-induced NF- $\mathrm{KB}$ activity $(\mathrm{C})$. The IFN $\gamma$ treatment $(48 \mathrm{~h})$ also inhibited the NF- $\kappa \mathrm{B}$ reporter activity that was induced by the p65 transfection (NF- $\mathrm{KB}$ p65) (D). Transiently transfected cells were treated with cytokines for the indicated time period before NF-KB reporter assays (C, D). (From J. Biol. Chem. 276, 13153, 2001 with permission)

180 cell death by IFN $\gamma / T N F \alpha$. MG132, a proteasome inhibitor that blocks $\mathrm{I} \kappa \mathrm{B} \alpha$ degradation, sensitized ME-180 cells to TNF $\alpha$ treatment alone (Fig. 6A). Dominant-negative I $\kappa \mathrm{B} \alpha$ transfection also induced TNF $\alpha$-susceptibility in otherwise resistant ME-180 cells (Fig. 6B). This suggests that $\mathrm{I} \kappa \mathrm{B} \alpha$ degradation and NF- $\kappa \mathrm{B}$ activation inhibit ME-180 cell death by TNF $\alpha$. The effect of IFN $\gamma$ on the TNF $\alpha$-mediated $\mathrm{NF}-\kappa \mathrm{B}$ activation pathway was examined. IFN $\gamma$ pretreatment attenuated the activation of the NF- $\mathrm{KB}$ reporter construct by TNF $\alpha$ (Fig. 6C). The same treatment also decreased the activation of the NF- $\kappa \mathrm{B}$ reporter by $\mathrm{p} 65$ transfection (Fig. $6 \mathrm{D})$. However, IFN $\gamma$ did not inhibit the translocation of p65 to nuclei, which was demonstrated by immunofluorescent staining. This suggests that IFN $\gamma$ inhibits transactivation of $\mathrm{NF}-\kappa \mathrm{B}$ without affecting p65 translocation after I $\mathrm{\kappa B}$ degradation. These results were confirmed by an electrophoretic mobility shift assay: IFN $\gamma$ pretreatment did not affect retardation of the nuclear complex-bound NF- $\kappa B$ probe after the TNF $\alpha$ treatment of ME-180 cells. The complex was supershifted by the anti-p65 or -50 antibody. These results suggest that IFN $\gamma$ synergies with TNF $\alpha$ in ME-180 cancer cell death by inhibiting the NF- $\mathrm{BB}$-mediated antiapoptotic pathway. However, the effect of IFN $\gamma$ on the TNF $\alpha$-mediated $\mathrm{NF}-\kappa \mathrm{B}$ activation in islet cell death was different in several aspects from that in the ME-180 cancer cell death. For example, the NF- $\kappa \mathrm{B}$ complex in pancreatic islet cells or insulinoma cells of NOD mouse origin was supershifted by anti-p65, but not by the anti-p50 antibody (Lee et al., unpublished data). These results might be related to the defective proteasome activity that was observed in the NOD mice (Hayashi and Faustman, 1999). IFN $\gamma$ also did not attenuate the TNF $\alpha$-induced NF- $\mathrm{KB}$ activation in pancreatic islet cell death. However, the NF- $\kappa \mathrm{B}$ activation seems to play an antiapoptotic role, as in the case of ME-180 cancer cell death (Lee et al., unpublished data). The role of NF- $\mathrm{NB}$ activation in autoimmune diabetes needs to be clarified by further studies including in vivo mouse experiments.

\section{Concluding Remarks}

While most studies in the apoptosis field focus on cell death by a single death effector, most cancer cells or normal cells may not be easily susceptible to a single cytokine, or single death effector in vivo. Otherwise, cancer cells will die too early to become a clinical tumor, and the host organism may be unusually prone to many diseases such as diabetes because of the death of normal tissues. Thus, death by multiple death effectors might be a more common phenomenon occurring in vivo. While we have studied only IFN/TNF synergism, other combinations such as IFN/TRAIL, FasL/IFN, and FasL/TNF 
synergism have been reported (Quirk et al., 1998; Kontny et al., 2001). While synergism between multiple death effectors confounds investigators and contradicts the reductionist view, such cytokine synergism, or even a combination of three or more, might be occurring in reality for effective cancer surveillance or pathological death of normal tissues in vivo. In the case of autoimmune diabetes, even the IFN/TNF synergism might be too simple. FasL or perforin has been shown to kill pancreatic $\beta$-cells in some circumstances (Kagi et al., 1997; Amrani et al., 1999). They may be effector molecules for pancreatic $\beta$-cell death at a specific stage of disease progression on a specific subset of lymphocytes, while they may not be the dominant death effectors in the majority of diabetogenic lymphocytes. For example, perforin on CD8+ $\mathrm{T}$ cells might play a critical role at an early stage of the disease progression (Kagi et al., 1997). The in vivo killing of cancer cells or normal tissues might be a very complicated process that requires different (multiple) death effectors at various stages of the disease progression.

\section{References}

Amrani, A., Verdaguer, J., Anderson, B., Utsugi, T., Bou, S. and Santamaria, P. (1999) Perforin-independent $\beta$-cell destruction by diabetogenic $\mathrm{CD} 8+\mathrm{T}$ lymphocytes in transgenic nonobese diabetic mice. J. Clin. Invest. 103, 1201-1209.

Chervonsky, A. V., Wang, Y., Wong, F. S., Visintin, I., Flavell, R. A., Janeway, C. A. and Matis, L. A. (1997) The role of Fas in autoimmune diabetes. Cell 89, 17-24.

Chu, J. L., Ramos, P., Rosendorff, A., Nikolic-Zugic, J., Lacy, E., Matsuzawa, A. and Elkon, K. B. (1995) Massive upregulation of the Fas ligand in lpr and gld mice: Implications for Fas regulation and the graft-versus-host disease-like wasting syndrome. J. Exp. Med. 181, 393-398.

Enari, M., Talanian, R. V., Wong, W. W. and Nagata, S. (1996) Sequential activation of ICE-like and CPP32-like proteases during Fas-mediated apoptosis. Nature 380, 723-726.

Fransen, L., Heyden, J., Ruysschaert, R. and Fiers, W. (1986) Recombinant tumor necrosis factor: its effect and its synergism with interferon- $\gamma$ on a variety of normal and transformed human cell lines. Br. J. Cancer Clin. Oncol. 22, 419-426.

Haskins, K. and McDuffie, M. (1990) Acceleration of diabetes in young NOD mice with a CD4+ islet-specific T cell clone. Science 249, 1433-1436.

Hayashi, T. and Faustman, D. (1999) NOD mice are defective in proteasome production and activation of NF-KB. Mol. Cell. Biol. 19, 8648-8659.

Henkart, P. A. (1994) Lymphocyte-mediated cytotoxicity: two pathways and multiple effector molecules. Immunity 1, 343346.

Hisahara, M., Shoji, S., Okano, H. and Miura, M. (1997) ICE/ CED-3 family executes oligodendrocyte apoptosis by tumor necrosis factor. J. Neurochem. 69, 10-20.

Itoh, N., Imagawa, A., Hanafusa, T., Waguri, M., Yamamoto, K., Iwasashi, H., Moriwaki, M., Nakajima, H., Miyagawa, M., Namba, M., et al. (1997) Requirement of Fas for the development of autoimmune diabetes in nonobese diabetic mice. J. Exp. Med. 186, 613-618.
Ju, S.-T., Cui, H., Panka, D. J., Ettinger, R. and A., M.-R. (1994) Participation of target Fas protein in apoptosis pathway induced by CD4+ Th1 and CD8+ cytotoxic T cells. Proc. Natl. Acad. Sci. USA 91, 4185-4189.

Kagi, D., Odermatt, B., Ohashi, P. S., Zinkernagel, R. M. and Hengartner, H. (1996) Development of insulitis without diabetes in transgenic mice lacking perforin-dependent cytotoxicity. J. Exp. Med. 183, 2143-2152.

Kagi, D., Odermatt, B., Seiler, P., Zinkernagel, R. M., Mak, T. W. and Hengartner, H. (1997) Reduced incidence and delayed onset of diabetes in perforin-deficient nonobese diabetic mice. J. Exp. Med. 186, 989-997.

Kagi, D., Vignaux, F., Ledermann, B., Burki, K., Depraetere, V., Nagata, S., Hengartner, H. and Golstein, P. (1994) Fas and perforin pathways as major mechanisms of $\mathrm{T}$ cell-mediated cytotoxicity. Science $\mathbf{2 6 5}$, 528-530.

Kang, S. J., Wang, S., Hara, H., Peterson, E. P., Namura, S., Amin-Hanjani, S., Huang, Z., Srinivasan, A., Tomaselli, K. J., Thornberry, N. A., Moskowitz, M. A. and Yuan, J. (2000) Dual role of caspase-11 in mediating activation of caspase-1 and caspase-3 under pathological condition. J. Cell Biol. 149, 613622.

Kano, A., Haruyama, T., Akaike, T. and Watanabe, Y. (1999). IRF-1 is an essential mediator in IFN- $\gamma$-induced cell cycle arrest and apoptosis in primary cultured hepatocytes. Biochem. Biophys. Res. Com. 257, 672-677.

Kim, S., Kim, J. Y., Lee, T. H., Suk, K., Cha, H.-S., Koh, E.-M., Yagita, H. and Lee, M.-S. Soluble Fas Ligand-Susceptible 'Memory' Cells in Mice but Not in Human: Potential role of soluble Fas ligand in deletion of autoreactive cells. Autoimmunity, in press.

Kim, S., Kim, K.-A., Hwang, D.-Y., Lee, T. H., Kayagaki, N., Yagita, H. and Lee, M.-S. (2000) Inhibition of autoimmune diabetes by Fas ligand: the paradox is solved. J. Immunol. 164, 2931-2936.

Kim, Y.-H., Kim, S., Kim, K.-A., Yagita, H., Kayagaki, N., Kim, K.-W. and Lee, M.-S. (1999) Apoptosis of pancreatic $\beta$-cells detected in accelerated diabetes of NOD mice: no role of FasFas ligand interaction in autoimmune diabetes. Eur. J. Immunol. 29, 455-465.

Kontny, H. U., Hammerle, K., Klein, R., Shayan, P., Mackall, C. L. and Niemeyer, C. M. (2001) Sensitivity of Ewing's sarcoma to TRAIL-induced apoptosis. Cell Death Differ. 8, 505-514.

Kumar, A., Commane, M., Flickinger, T. W., Horvath, C. M. and Stark, G. R. (1997) Defective TNF- $\alpha$-induced apoptosis in STAT1-null cells due to low constitutive levels of caspases. Science 278, 1630-1632.

Lee, M.-S., Kim, S., Chung, J. H., Lee, M.-K. and Kim, K.-W. (1999) Fas is expressed in murine pancreatic islet cells and an insulinoma cell line but does not mediate their apoptosis in vitro. Autoimmunity 29, 189-199.

Quirk, S. M., Porter, D. A., Huber, S. C. and Cowan, R. G. (1998) Potentiation of Fas-mediated apoptosis of murine granulosa cells by interferon-gamma, tumor necrosis factoralpha, and cycloheximide. Endocrinology 139, 4860-4869.

Reap, E. A., Roof, K., Maynor, K., Borrero, M., Booker, J. and Cohen, P. L. (1997) Radiation and stress-induced apoptosis: A role for Fas/Fas ligand interaction. Proc. Natl. Acad. Sci. USA 94, 5750-5755.

Suk, K., Kim, S., Kim, Y.-H., Kim, K.-A., Chang, I., Yagita, H., 
Shong, M. and Lee, M.-S. (2001a) IFN $\gamma / T N F \alpha$ Synergism as the Final Effector in Autoimmune Diabetes: A key role for IRF-1 in pancreatic $\beta$-cell death. J. Immunol. 166, 4481-4489.

Suk, K., Kim, Y. H., Chang, I., Kim, J. Y., Choi, Y. H., Lee, K. Y. and Lee, M. S. (2001b) IFNalpha sensitizes ME-180 human cervical cancer cells to TNFalpha-induced apoptosis by inhibiting cytoprotective NF-kappaB activation. FEBS Letters 495, 66-70.

Tamura, T., Ishihara, M., Lamphier, M. S., Tanaka, N., Oishi, I., Aizawa, S., Maatsuyama, T., Mak, T. W., Take, S. and Taniguchi, T. (1995) An IRF-1-dependent pathway of DNA damage-induced apoptosis in mitogen-activated $\mathrm{T}$ lymphocytes. Nature 376, 596-599.

Tanaka, M., Suda, T., Haze, K., Nakamura, N., Sato, K., Kimura, F., Motoyoshi, K., Mizuki, M., Tagawa, S., Ohga, S., et al. (1996) Fas ligand in human serum. Nat. Med. 2, 317-322.

Wang, S., Miura, M., Jung, Y.-K., Zhu, H. and Yuan, J. (1998) Murine caspase-11, an ICE-interacting protease, is essential for the activation of ICE. Cell 92, 501-509.

Wang, Y., Pontesilli, O., Gill, R. D., La Rosa, F. G. and Lafferty, K. J. (1991) The role of CD4+ and CD8+ T cells in the destruction of islet grafts by spontaneously diabetic mice. Proc. Natl. Acad. Sci. USA 88, 527-531.

Watanabe, D., Suda, T., Hashimoto, H. and Nagata, S. (1995) Constitutive activation of the Fas ligand gene in mouse lymphoproliferative disorders. EMBO J. 14, 12-18.

Wicker, L. A., Miller, B. J. and Mullen, Y. (1986) Transfer of autoimmune diabetes mellitus with splenocytes from nonobese diabetic (NOD) mice. Diabetes 35, 855-860.

Wofsy, D., Hardy, R. R. and Seaman, W. (1984) The proliferating cells in autoimmune MRL/lpr mice lack L3T4, an antigen on "helper" $\mathrm{T}$ cells that is involved in the response to class II major histocompatibility antigens. J. Immunol. 132, 2686-2689.

Yamada, K., Takane-Gyotoku, N., Yuan, X., Ichikawa, F. and Nonaka, K. (1996) Mouse islet cell lysis mediated by interleukin-1-induced Fas. Diabetologia 39, 1306-1312. 